\title{
Da invenção mais impura: uma montagem de Orfeu em Herberto Helder
}

\author{
Mariana Pereira Guida*
}

\section{Resumo}

Este artigo vale-se do mito de Orfeu enquanto tópica reiteradamente revistada na poesia moderna para analisar duas possibilidades de leitura do poeta trácio na obra do poeta Herberto Helder. A hipótese central é a de que, embora distintos, ambos guardam em si a implicação de metamorfose e finitude engendrada pela metáfora no projeto do poema contínuo, tendo em vista a escrita como um procedimento paradoxal de inscrição e apagamento articulado por imagem e som na enunciação lírica. Para tanto, a obscuridade inscrita no gesto autoral será perscrutada a partir do recurso do corte na montagem cinematográfica, considerando o princípio fílmico da poesia helderiana e o modo pelo qual ela se apropria do mito de Orfeu a partir da recitação poética como uma força que opera no horizonte de uma alteridade radical, fundadora de um idioma próprio, no qual origem e fim simultaneamente condicionam a interdição e a abertura ao sentido.

Palavras-chave: Herberto Helder. Orfeu. Imagem. Morte. Montagem.

* Mestre em Letras - Estudos Literários pela Universidade Federal de Minas Gerais - UFMG. Possui Licenciatura Plena em Letras - Português pela Universidade Federal de Alfenas Universidade Federal de Alfenas (UNIFAL-MG). 


\title{
From the most impure invention: a performance of Orpheus in Herberto Helder's work
}

\begin{abstract}
This article draws on the myth of Orpheus as a topic repeatedly recovered in modern poetry to analyze two possibilities for reading the Thracian poet in the work of the poet Herbeto Helder. The central hypothesis is that, although distinct, both hold the implication of metamorphosis and finitude engendered by metaphor in the design of the continuous poem, in view of writing as a paradoxical procedure of inscription and erasure articulated by image and sound in the enunciation lyric. Therefore, the obscurity inscribed in the authorial gesture will be examined from the point of cut in cinematographic montage, considering the filmic feature of Helder's poetry the way in which it appropriates the myth of Orpheus from the poetic recitation as a force that operates in the perspective of a radical alterity, founder of a specific language, in which origin and end simultaneously condition interdiction and openness to meaning.
\end{abstract}

Keywords: Herberto Helder, Orpheus, Image, Death, Montage.

Recebido em: 30/09/2020 // Aceito em: 23/11/2020 


\section{0 gesto autoral sob o olhar de Orfeu: linhas gerais para uma leitura da imagem em Herberto Helder}

Esboçando diferentes matizes, entoando seu canto sob uma pletora melódica tão diversa quanto a própria arte, o mito de Orfeu atravessou as mais diversas manifestações artísticas ao longo do tempo e manteve-se particularmente significativo à imaginação e aos processos criativos modernos. Há algo de extasiante e irremediavelmente aterrador no poder encantatório de sua lira e na condição trágica de seu destino que propicia a "metamorfose do mago provinciano no mensageiro dos tempos modernos" (BRUNEL, 2003, p.62); seja pela capacidade de reunir "tanto a ruptura quanto a continuidade [que], então, acompanham a dissolução das formas modernas" (HASSAN,1982, p.11) ${ }^{1}$ ou simplesmente pela "potência do erro" (BLANCHOT, p.170) que as leituras do mito suscitam.

Assim, a participação ativa nos processos de gênese e aniquilamento do mundo, ou seja, o modo pelo qual o homem não apenas é submetido às vicissitudes da natureza que o cerca, mas também parte constitutiva de um continuum - segundo Hans Blumenberg, parte de uma "contextura de opostos que não se abolem" - dá indícios da concretude física que caracteriza o cosmo helenístico (BLUMENBERG, 2010, p.110) em que se gesta o mito do poeta tal como o conhecemos. ${ }^{2} \mathrm{O}$ impulso de racionalização da potência envolvida na articulação desses opostos (o dado da teleologia que lhe atribuem os estoicos e o dado da autossuficiência da criação contínua que lhe atribui Agostinho) conformaria, segundo Blumenberg, a percepção

1 No original: "Both schism and continuity, then, attend the dissolution of modern forms". Tradução nossa.

2 Cf: Bernabé, Alberto: Orfeo, una "biografía" compleja. In: BERNABÉ, Alberto; CASADESÚS, Francesc. Orfeo y la tradición órfica. Un reencuentro. Ediciones Akal, S. A., 2008, p.15-32. 


\section{Da invenção mais impura: uma montagem de Orfeu em Herberto Helder}

moderna da relação entre tékhne e physis notadamente expressa em Nicolau de Cusa "desloca-se, de repente, a ênfase da expressão da vontade divina sentida na criação para o caráter de privação implícito na não criação" (BLUMENBERG, 2010, p.126). Os artefatos da criação artística passam a ser tomados pela ordem do possível e, nesse sentido, o próprio Cusa pode nos oferecer a visada moderna de Orfeu. Em The Legitimacy of the Modern Age, Blumenberg chama a atenção para o fato de Cusa, em De Ludo Globi, tratar o astrolábio de Ptolomeu e a Lira de Orfeu como exemplos da "novidade da invenção" na medida em que "que estão estruturalmente fechadas em si mesmas e, ao mesmo tempo, são orientações mediadoras" (BLUMENBERG, 1983, p.536). ${ }^{3}$

No que diz respeito a lírica moderna, esta associação que oscila entre metamorfose e finitude na enunciação poética pode ser verificada sob um conjunto de "categorias predominantemente negativas", como as definiu Hugo Friedrich (1978, p.21), nas quais a obscuridade e a dissonância que passam a viger entre a poesia e o mundo, sobretudo após os experimentos de vanguarda do século $\mathrm{XX}$, deflagram uma emergência da visualidade no âmbito das artes e, de modo mais amplo conformam o que Gottfried Boehm definiu como "virada icônica": "uma mudança hermenêutica" promovida pelo "aumento exponencial das formas de comunicação visual" (ALLOA, 2019, p.93-94). No que diz respeito ao discurso lírico, o projeto do livro mallarmaico pode ser tomado como exemplo notável da "ferida exposta" pelos experimentos vanguardistas, no sentido de atribuir à tensão entre os domínios do dizível e do visível a espessura que lhe é constitutiva, de modo que a escrita se evidencia como "a

\footnotetext{
3 "(...) the astrolabe of Ptolemy and the lyre of Orpheus are exemplary novelties of invention, which are structurally closed in themselves and yet at the same time are mediating orientations. remed conjectures, as it were, for knowledge".
} 
ocupação de um espaço que não se reduz a um suporte - flumen, codex, página - linear, plano ou espacial (..). A letra é o espaço mínimo, inevitável, de toda escrita; ela é também o sintoma em sua mobilidade" (COMPAGNON, 1996, p.161).

A questão espacial implicada no princípio da mobilidade suscitado por Compagnon torna o caso de Orfeu especialmente interessante à investigação das implicações entre autoria e representação na modernidade, seja pela visada de uma condição de crise na qual o poeta encena a si próprio como a vítima da limitação que lhe impõe a linguagem e o algoz, que ratifica este dano na sintaxe dilacerada de seus versos (SISCAR, 2007), seja pelo acirramento entre totalidade e fragmento que as relações entre subjetividade e textualidade nela assumem, na medida em que "o texto da modernidade e da pós-modernidade" deslocase "no cruzamento de duas coordenadas", a saber: "o sujeito enquanto se sistematiza/fragmenta no texto e o texto enquanto fragmenta/ sistematiza o sujeito" (EIRAS, 2005, p.46).

Esse aspecto figurativo e contingente sob o qual conjugamse continuidade e ruptura conduzirá nosso percurso pela poesia de Herberto Helder, poeta madeirense que se estabeleceu na cena literária portuguesa da virada do milênio e cujo epíteto de obscuro, do qual o poeta se valeu com perspicácia audaciosa, será o ponto de partida para o cotejo com o mito de Orfeu aqui pretendido. A revisitação da cena ancestral da criação órfica aqui tenderá a perscrutar, sobretudo, como é sob o horizonte de uma alteridade radical e do movimento por ela engendrado que Orfeu ressoa nos versos de Herberto, o que parece prolífico à crítica que se detém sobre essa obra fortemente associada a uma certa tradição simbolista/surrealista, cuja alta coesão dos meios de realização não impediu a transmutação constante em 


\section{Da invenção mais impura: uma montagem de Orfeu em Herberto Helder}

função da sua pretensão à criação de um idioma único e singular. Revisitar o mito do poeta trácio pela perspectiva de completude de uma poesia que se coloca à revelia de um fim, nesse sentido, demanda observar as inflexões do gesto autoral na cena de escrita engendrada no poema, na qual o poeta figura não como "o demiurgo órfico revelador do ser mas o criador de um jogo" (EIRAS, 2005, p.392), no qual uma " forma-poema torna-se forma-mundo" (LOPES, 2003, p.12).

As colocações expostas neste texto provêm de uma investigação mais ampla, na qual se perscrutou a relação entre metamorfose e finitude nas últimas publicações do autor a partir do pressuposto teórico da relação entre poesia e pensamento no projeto do poema contínuo helderiano. A visada comparatista que perpassou poesia e filosofia a partir da análise do papel da metáfora na obra de Helder será retomada para a reflexão sobre a figuração do gesto autoral na sua poesia e no mito de Orfeu, tendo em vista a escrita como o procedimento paradoxal de inscrição e apagamento articulado sob imagem e som na enunciação lírica. Nesse sentido, a abordagem comparada também subsidia a leitura_deliberadamente fílmica dessa obra, a indistinção entre poesia e cinema nela empreendida desde as primeiras publicações do autor. Em tal indistinção é notória uma visão da literatura que tenderá a se consolidar com o próprio paradoxo entre contingência e transitividade da criação artística moderna, que leva à exaustão o prenúncio de um fim iminente e constantemente reiterado: "ela afirma e nega ao mesmo tempo a arte, decreta simultaneamente sua vida e sua morte, sua grandeza e sua decadência" (COMPAGNON, 1999, p.10).

Diretamente vinculada à assimilação dessa condição paradoxal da linguagem, a "virada linguística" do século XX 
pode ser associada à emergência do paradigma icônico de trata Alloa, sob a visada de uma reiteração da autorreflexividade do sistema epistêmico, na medida em que "a imagem é sempre deficiente e excessiva em sua sobrepresença sensorial" (ALLOA, 2019, p.105). De modo análogo, a visualidade da cena órfica aqui suscitada lança o poeta ao impasse de um "duplo luto sucessivo" análogo ao que conduz o olhar de Orfeu "para uma Eurídice perdida, reencontrada e novamente perdida" (BRUNEL, 2003, p.48). Assim também o princípio de um poema contínuo que se pretende Poesia Toda faz da matapoesia helderiana um exercício constante de exploração da deficiência e do excesso constitutivos da linguagem: "a relação que os nomes mantêm com os seus modificadores desestabiliza esta visualidade fazendo-a coexistir com uma espécie de cegueira vinda das conexões inusitadas, da tensíssima montagem das imagens" (MARTELO, 2016, p.86).

$\mathrm{Na}$ esteira dessa leitura do gesto autoral articulado sob mobilidade e contingência na metáfora ${ }^{4}$ helderiana, este artigo tomará dois poemas nos quais Orfeu prefigura a persona autoral na poesia, perseguindo os modos pelos quais neles o poeta apresenta-se em ausência na enunciação lírica. A reflexão buscará revisitar a discussão da obscuridade, cara à crítica e ao próprio autor, observando o rosto do poeta como reflexo de um "espelho eletrocultado" - espécie autônoma e espectral que se inscreve na cena da escrita pelo gesto sacrificial do suicídio - na propagação do canto. Do percurso que passa pelo impasse entre a autoreferencialidade e a exterioridade na literatura moderna até suas implicações para a problemática do "mito do poeta" na poesia tal qual a coloca Svetlana Boym, pretende-se estabelecer uma via especulativa da contemporaneidade de Orfeu em Helder

4 Em função da adesão à metaforologia de Blumenberg e ao recorte crítico da intersecção entre poesia e cinema em Herberto Helder, a partir daqui os termos metáfora e imagem serão adotados em equivalência. 


\section{Da invenção mais impura: uma montagem de Orfeu em Herberto Helder}

a partir das encenações de uma "morte figurativa" (BOYM, 1991, p.29) que encerra o poeta na poesia.

Desde logo, apresenta-se como hipótese de leitura um olhar para a obscuridade do gesto autoral que procura identificar em que termos, na poesia de Helder, ele aponta para o "ponto" esquivo da "outra noite" para o qual se desloca o olhar de Orfeu (BLANCHOT, 1987, p.171), ou seja, como a instabilidade entre o visível e o invisível na imagem do rosto em Helder desloca-se, inexoravelmente, para a morte, pois se, por um lado, conjugam em si o potencial da criação, o "poema como poiesis do mundo" (GUSMÃO, p.387), por outro, numa outra morte (LOPES, 2003, p.31), são literalmente dilacerados pela impossibilidade do registro da experiência, pelo impulso de "fugir à morte como um estado - o estado de imagem definitiva, separada daquilo que é imagem - através do morrer" (LOPES, 2003, p.48). Enquanto realidade irrealizável, a morte emerge no gesto sacrificial que o autor empreende ao escrever e sob o horizonte de uma exterioridade impossível. Assim, ela dá a ver a própria dimensão projetiva da linguagem na condição de uma força, uma movência, um trabalho que é citacional, recitativo, tal como o trabalho do luto, na medida em que envolve uma demanda, uma solicitação: "se ocupa de meu desejo, e o objeto assinalado que eu expulso do texto a fim de conservá-lo como memória de uma paixão (a da solicitação), esse objeto não passa de um resíduo, um dejeto, um logro, um fetiche e um simulacro que se somam ao meu estoque de cores" (COMPAGNON,1996, p.25-26).

Arriscar uma incursão pela poesia de Herberto Helder que parta da autobiografia romanceada de Apresentação do Rosto, livro apreendido pela censura em 1968 e posteriormente excluído da obra pelo autor, pode ser um modo de lançar-se 
problematicamente em uma emboscada e corroborar o gesto criminal que "comete" o poema, inscrevendo-se e ao mesmo tempo anulando-se nessa escrita de modo a apontar para o silêncio que lhe é subjacente. É também se arriscando no viés problemático reclamado por este livro que se marca em ausência na produção de Herberto que Diana Pimentel articula uma revisão crítica que enceta as ressonâncias de Apresentação do Rosto (1968) em Photomaton \& Vox (1979), livro que, juntamente com Os Passos em Volta (1963), pode ser lido como ars poética do texto helderiano (DAL FARRA apud PIMENTEL, 2016, p.78). Neste sentido, a caminhada pelas ranhuras biografáveis de Apresentação do Rosto em Photomaton \& Vox aqui iniciada tem em perspectiva o entrelaçamento entre vida e obra que, no seu caso, reivindica-se sob um ímpeto de presença que se dá ostensivamente, visivelmente e, sobremaneira, cinematograficamente, uma vez que nele imagem e som conjugam, respectivamente,

(...) um retrato de autor (photomaton) a uma visão de autoria em acto, centrando-se mais nas condições do processo libertário ao qual Herberto Helder chama criar um estilo, um idioma (voz, vox), ou seja, centrandose nas condições de manifestação da língua singular, única, desta poesia. (MARTELO, 2016, p.34)

Considerada a premissa da "autoria em ato" levantada por Rosa Martelo, dois aspectos importantes da poesia de Helder devem ser demarcados no horizonte da via especulativa que se pretende seguir: 1) A radicalidade da montagem pretendida pelo poema contínuo - "o 'poema' toma o lugar da 'poesia' ou está por ela” (GUSMÃO, 2009, p.131) - sobretudo a partir da recolha de 2001, segundo ; 2) a reiterada inscrição do gesto autoral seguida da aniquilação impingida pela conformação do 


\section{Da ínvenção mais impura: uma montagem de Orfeu em Herberto Helder}

poema no tempo - “'Herberto Helder' emigra da sua condição de nome de autor (que reenvia para um indivíduo humano concreto) para a condição de texto, de fragmento textual de um título." (GUSMÃO, 2009, p.131). A fusão entre o poeta e o poema remonta ao arcabouço cultural do europeu no qual o mito de Orfeu paulatinamente se consolida como mito da poesia, porém já sob a visada saturada de modernidade do período pós-vanguardas, que resulta aqui no cruzamento de dois impasses - duplo luto - que , o da legibilidade/ilegibilidade e o da visibilidade invisibilidade, na cena da escrita poética como o corpo anônimo do ator na escritura vocal empreendida em um filme (BARTHES,1987, p.85), o corpo necessário à fruição do texto é um corpo outro, puramente sensório, indispensável à sua figuração: "o próprio texto, estrutura diagramática, e não imitativa, pode desvelar-se sob a forma de corpo, clivado em objetos fetiches, em lugares eróticos" (BARTHES, 1987, p.71).

Nesse ponto reside o caráter "evasivo" do mito cultural do poeta de que nos fala $\operatorname{Boym}^{5}$ (1991, p.29), ele próprio da ordem da imaginação, da invenção, no âmbito da imaginação e do “discurso não verbal” e "não escrito" (BOYM, 1991, p.29) que é próprio da poesia. De modo análogo, à face trágica do mito do Orfeu - o distanciamento da natureza e a negatividade que encerram o poeta - caberia, sem grandes problemas, a elaboração sobre a crise da poesia moderna - reitere-se: da poesia - feita por Marcos Siscar: "Trata-se, antes, de uma dramatização - não exatamente afirmação ou sintoma - da violência simbólica pela qual se instituem os laços culturais que dão sentido à poesia" (SISCAR, 2007, p.180-181).

\footnotetext{
5 "The cultural myth largely relies on unwritten but widely accepted, naturalized nonverbal discourse, on the power of the image and its semivisible, heavily codified iconography, as well as on cultural fashioning and social masks used in the 'theater of everyday life"'.
} 
Para verificar como tais aspectos constituem-se como linhas de força do projeto do poema contínuo, recorre-se ao excerto final de (a paisagem é um ponto de vista), um dos metatextos que se espraiam pela poética deambulatória de Photomaton \& Vox, no qual se resgata, sob um tom ímpio que é recorrente na lírica helderiana, o estado da arte das relações entre arte e natureza. Após assegurada "aristotelicamente a arte de imitar a natureza" e alguns eventos que a sucederam - a "expulsão da natureza pela arte", as "meditações sobre a gravidade", o "divertimento singularmente demoníaco" da psicanálise e Rimbaud com seu Le Bateau Ivre - tem-se, agora, a apresentação:

E há ainda a apresentação, novo estilo de desavença. Pois vai a gente apresentar o que está presente? A ausência é que deveria apresentar-se, pois tarda na ausência. Aqui fala-se de uma estratégia inabitual. Forçoso seria desentranhá-los da obscuridade, aos obscuros, aos ausentes. Apresentá-los. (...) (HELDER, 1995, p.63)

Os obscuros, estes que "acabaram de chegar da ausência" e que devem ser apresentados... quem são?

$\mathrm{O}$ texto, tão obscuro quanto o poeta que requer para si a insígnia da obscuridade, não deixa certo ao leitor de quem se trata. Entretanto, podemos vislumbrar uma resposta a partir de outro excerto do mesmo livro, agora de (a carta do silêncio):

Vejo o suicídio de Trakl, Sá-Carneiro, Hart Crane, Sylvia Plath, Celan.

O outronímico ${ }^{6}$ ilumina, com a reserva do oposto, o que foi dito para relevo do silêncio oferecido por umas quantas palavras em voz rítmica, modulações sensíveis, o estímulo entre os testículos e a garganta, com os olhos radiosos por cima.

Radicalmente, a mudez personifica o duplo.

$\overline{6}$ Expressão pela qual Herberto refere-se a Fernando Pessoa. 
Os próprios espelhos, não sei de que modo apresentarão as pupilas luciferinas de Georg; Sá-Carneiro com as veias luzindo de estricnina; Sylvia e as queimaduras dos eletrochoques por dentro da cabeça; os outros, de pulmões fechados pela água.

Não apresentam nada, nada, só um clarão que vem centripetamente das periferias obscuras e salta ao meio: o meio é nosso rosto urdido a expensas da ausência e exemplo fraternos.

Essa mesma luz engole-nos, e um dia, olhando, não veremos o rosto.

Tudo isto executado numa espécie de expansão conclusiva do recuo, pacto com o limite do afastamento: um espelho eletrocutado (HELDER, 1995, p.173-174)

Não seria absurdo pensar, assim, que aquilo que o poeta apresenta de si é a morte: este corpo atento, aberto "à suspeita de que quando escrevemos algo vai acontecer" (HELDER, 1990, p.29), é, juntamente com toda a matéria e os afetos que lhe permeiam, tomado por esse clarão do qual surge o poema. A imagem do espelho eletrocutado suscitada na passagem de (a carta do silêncio) é, no mínimo, curiosa. Nele ocorre uma experiência não muito bem definida que envolve a luminescência e a obscuridade, o contato e o distanciamento dos corpos envolvidos no fenômeno. É notável também como, em Herberto Helder, o espelho é imagem recorrente e jamais associada ao senso comum do objeto refletor de imagens, algo que já o prefácio/poema de A Colher na Boca (1961) anuncia: “(...) - E de tudo os espelhos são a invenção mais impura. " (HELDER, 2014, p.11). 


\section{A imagem cinematográfica: o espetáculo da morte}

Neste sentido, um livro que parece intimamente ligado à percepção da morte como intersecção entre vida e obra na relação do poeta com a tradição é Ouolof (1997): nomeadamente, um conjunto de poemas "mudados para o português" que se inicia com uma versão "ferozmente parcialíssima" - e, por pouco, homônima - do poeta e tradutor Zbigniew Herbert, ressoando o canto ancestral outrora emitido no livro de 1968, aqui sob inflexões de culturas e tradições diversas que vão de evocações Maias a cantos dos Índios Caxinauás, da Amazônia. Há, contudo, um lugar decisivo e determinante na linguagem de Ouolof em que se instaura a morte do poeta. Nele apresentam-se, pela ausência, poetas nos quais a morte, o suicídio ou a autodestruição são, para além de elementos biográficos notórios, temas centrais de suas obras, como Rainer Maria Rilke, Marina Tsvetaeva, Malcolm Lowry e Jean Cocteau. Tendo em vista a leitura que se pretende fazer de Orfeu neste texto, este último parece ser particularmente interessante, pois, para além da concepção de correspondência direta entre poesia e cinema compartilhada entre o poeta/realizador e o realizador/poeta, é o Orfeu (1950) de Cocteau que o liga a Herberto em Ouolof. Do conjunto de "poemas mudados para o português" por Herberto em Ouolof (1997), um dos poemas de L'Ange Heurtebise (1926), de Jean Cocteau, permitem-nos perceber aspectos dessa morte encenada no gesto autoral:

Anjo Heurtebise, vestido de água

Meu anjo amado, a graça

Dói-me. Deus

Tortura-me, dói-me.

Em mim o demónio é tartaruga, animal 
Outrora melodioso. Vem

Sai da ágata

Áspero fumo, ó velocidade que mata.

Nos teus patins de diamante risca

O espelho dos doentes

As paredes

As paredes

Têm ouvidos

E os espelhos

Têm olhos de amante

(HELDER, 1997, p.85-86).

Após evocar o "seu" anjo Heurtebise no primeiro verso do poema e prolongar tal evocação pelos versos seguintes até uma "aparição" - "Sai da ágata/ Áspero fumo, ó velocidade que mata. /Nos teus patins de diamante risca/ O espelho dos doentes" -, o sujeito lírico propaga um "eco" das "paredes" entre os versos. Ao som guardado pelo conjunto maciço e opaco das paredes interpõe-se a superfície especular: silenciosa, visual e fluida, tanto na poesia de Cocteau quanto na de Herberto, ela não diz respeito ao objeto refletor de imagens, mas sim a uma espécie de corruptela - "dos doentes" - responsável pelo fascínio da imagem, uma invenção impura (HELDER, 2014, p.11) que atrai o olhar do poeta sob o princípio da representação, mas revela sempre um outro - figura do desejo - com "olhos de amante".

Sob o eco de Cocteau e de Orfeu - o que se pode verificar mais claramente na trilogia cinematográfica, Sangue de Um Poeta (1932), Orfeu (1950) e O Testamento de Orfeu (1960), de Cocteau - é possível identificar tanto a figura do anjo, quanto a do espelho como tônicas que, em certa medida, modulam o diálogo entre os filmes. À luz das considerações de Maurice Blanchot (1987) e Charles Segal (1989) sobre o mito, tais imagens tornam-se ainda mais significativas se, por exemplo, atribuímos ao anjo as noções de inspiração, desejo e amor, ao espelho as 
de arte e obra e à personagem de Orfeu a sentença da morte que lhe "assombra" enquanto chancela. Isso porque ambos parecem pontuar o caráter decisivo da permanência do indecidível em cuja "obra, pela inspiração, está tão comprometida quanto Orfeu está ameaçado", de modo que o gesto de Orfeu oscila entre "a capacidade da arte, da poesia, da linguagem - 'retórica e música” - de triunfar sobre a morte” pelo “poder criativo da arte se alia ao poder criativo do amor" e "o fracasso da arte antes da necessidade última, a morte" (SEGAL, 1989, p.2).

Assim, se o poema puder ser pensado como uma invenção tão impura quanto o espelho, muito antes de refletir a imagem do poeta o comunica com um fora, um exterior para além de si e a partir de si, e após a confissão, em segredo, de Heurtebise "Os espelhos são portas pelas quais a Morte vai e vem" - Orfeu passa a dispor da habilidade de habitar os dois mundos, dos vivos e dos mortos. A distorção do caráter refletor do espelho, operando sob o mesmo princípio da relação que os nomes e seus modificadores estabelecem na sintaxe helderiana, põe em questão o ideal de transparência da linguagem ao evidenciar seu caráter contingente e relacional, algo que a espectralidade da imagem cinematográfica condensa de maneira exitosa em termos de fatura estética.

Nesse sentido, a afinidade da poesia helderiana com o cinema relaciona-se intimamente com a "potência do falso" que Deleuze identifica na superfície especular: "uma instância de dupla face, igualmente presente na série significante e na série significada" (DELEUZE, 1998, p.43). Sob essa perspectiva, a instância especular guarda a própria lógica do sentido, sobretudo quando se tem em conta a dinâmica relacional que ela engendra, pois "se os termos de cada série são relativamente deslocados, 


\section{Da ínvenção mais ímpura: uma montagem de Orfeu em Herberto Helder}

uns com relação aos outros, é porque primeiramente, em si mesmos, elas têm um lugar absoluto, mas este lugar absoluto se acha sempre determinado por sua distância deste elemento que não para de se deslocar relativamente a si mesmo nas duas series" (DELEUZE, 1998, p.43)

Se o espelho constitui então esse espaço de puro deslocamento, há de se considerar esse outro que se interpõe ao poeta de maneira insidiosa, com "olhos de amante". Assegurando a possibilidade de uma experiência do fora, ele provoca a morte figurativa do sujeito desintegrado na enunciação lírica pela projeção afetiva, pelo endereçamento a um ponto de contato, uma exterioridade que prefigura um ponto de totalidade "fora dela em face dela - punctum proximum do olhar do poeta" (NANCY, 2014, p. 128). O toque aqui entendido como esse endereçamento de um silêncio conduzirá nossa leitura por este segundo desdobramento de Orfeu em Herberto Helder, que diz respeito ao arrebatamento da morte como abertura, investimento em uma alteridade radical.

A imagem do nome Herberto Helder reduzido à mera "condição textual" sugerida por Manuel Gusmão, condensa sucinta e fortemente a premissa da obscuridade aqui atribuída ao gesto autoral, bem como a elaboração que lhe é dada pelo poeta sob o ponto de vista da fatura estética. Assim, como o sujeito que propaga o canto na cena poética do presente é uma "letra muda que se repete" (GUSMÃO, 2012, p.5), aqueles que o precederam lhe chegaram obscuros, em alguma medida secretos pela tensão do toque. Filiam-se pelo elo do silêncio que os torna presentes nesse processo de fundação de um idioma no qual origem e fim simultaneamente condicionam a interdição e a abertura ao sentido. 


\section{A imagem cinematográfica: a morte e a abertura à alte- ridade}

A perspectiva da filiação é aquela pela qual se solicita o nome de António Ramos Rosa como um elo importante para a associação de Herberto a essa tradição da obscuridade anteriormente mencionada. Herberto Helder - Poeta órfico, sob este aspecto, fez parte das primeiras recensões que se detiveram sobre o encantamento sombrio dessa poesia, de modo que dentre os vários apontamentos ali pertinentes à discussão proposta neste artigo vale ressaltar a observação: "seus temas se transcendem para um só tema ou num só acto de transcensão para o originário, para este ponto de extrema violência em que se anulam os contrários e onde a eternidade se revela no instante" (RAMOS ROSA, 1962, p.155). Mesmo se tratando de uma análise que interpela a obra de Herberto ainda nos seus primeiros poemas, os apontamentos que Ramos Rosa nela tece não deixam de ser pertinentes à toda produção que se seguiu a partir daí, não tanto pela recorrência do que poderia se tratar de uma temática órfica - "A linguagem de Herberto Helder, no entanto, não repousa muito nas habituais palavras-chave e, se ficarmos na enumeração delas é pouco, teorizar a partir delas é arriscado" (BELO, 2002, p.189) - mas sim pelo impulso de reunir às idiossincrasias das vanguardas que reencenaram Orfeu pela via da disjunção completa, a contingência e a limitação históricas que postergam esse gesto sacrificial extremo pela mediação do presente.

A aposta em propiciar a esse "acto de transcensão para o originário" pela precariedade e pela trivialidade do cotidiano enseja a revisitação da obscuridade no gesto autoral sob a 


\title{
Da invenção mais impura: uma montagem de Orfeu em Herberto Helder
}

perspectiva afetiva da relação de desejo e luto implicada na poesia helderiana ao apontar para esse ponto de voragem que que a morte como horizonte. Ele se dá a partir de uma exterioridade que afirma uma abertura ao sentido, um "acesso" enquanto "passagem, uma via ou um caminho, e que também o afirma como uma presença, uma invasão" (NANCY, 2016, p.147) de sentido, de modo que é, portanto, sob essa visada da filiação que se recorre ao nome de Ramos Rosa. A inscrição de um nome como um endereçamento anônimo, uma carta do silêncio, permite abordar a escrita enquanto um trabalho, um trabalho que envolve dimensões de citação, tradução e luto, pelo qual o poeta destina sua própria finitude a um outro que a tocará nos seus versos. Por isso, é válido recorrer a Poemas Canhotos (2015) um livro atravessado pela finitude em diversos aspectos, inclusive o caráter de inacabamento que o aproxima da "montagem elementar" de Warhol que o autor, em carta a Gastão Cruz (HELDER, 2015b, p.152), dizia buscar em seus versos e que Rosa Maria Martelo identifica como "a presença de uma matéria verbal não burilada ou mesmo rude, mas na qual Herberto Helder sempre confiou em termos de renovação estética” (MARTELO, 2016, p. 50). Dentre os poemas do livro, destaca-se o seguinte:

\author{
o António Ramos Rosa estava deitado na cama \\ contra a parede \\ e deu meia volta sobre si mesmo \\ e ficou de cara voltada contra a parede \\ e fechou os olhos \\ e fechou a boca \\ e ficou todo fechado \\ e então morreu todo \\ fundo e completo de uma só vez \\ e apenas ele no tempo e no espaço \\ e só agora passado ano e meio eu compreendo
}


como era preciso ser assim tão íntimo para sempre tão compacto

mais que o mundo inteiro

- e ele sou eu

(HELDER, 2015, p.34-35)

O poema inicia-se com uma irrupção, com o abalo de um estado - o poeta deliberadamente "deitado" - gerado por um movimento necessariamente opositivo - 180 graus da meia volta - e reflexivo - "sobre si mesmo" - que impossivelmente termina na contrariedade do ponto de partida. A interdição posta em causa pela intransitividade de tijolos e concreto a essa altura nos seria patente se não nos lembrássemos do presságio do poema de Ouolof, "As paredes/têm ouvidos". Os versos seguem sob um paralelismo que narra uma paulatina anulação exercida pelo poeta sobre si próprio e culmina na sua morte com a transmutação física do corpo em mero fragmento textual, uma centelha capaz de conter uma totalidade "e apenas ele no tempo e no espaço", encerrando o círculo que une o início e fim numa completude que enseja um "mais que o mundo inteiro e que é mantida pelo sopro de um outro rosto, obscuro "- e ele sou eu”.

Quando Ramos Rosa "morre todo" no poema, o poeta torna-o mais fatalmente vivo na poesia - " (...) tão íntimo para sempre" (HELDER, 2015, p.39) - e, de algum modo, torna-se também parte da carne daqueles que a entoarão - "- e ele era eu" (HELDER, 2015, p.39) -, parte do terramoto que o toma antes de reverberar "canhoto" na palavra. A revolução empreendida pela morte do poeta no poema é a única em que o humano é capaz de reunir o possível e o factual em um trabalho, uma obra que, no limite é o único telos, a única razão da própria vida daquele que escreve. Assim, Herberto não apenas toma para si a tradição poética com a paixão e a intensidade do leitor, como 
também investe nesse envolvimento erótico da leitura como um potencial multiplicador, a própria força do poema contínuo. Não por acaso, Herberto vai ao poeta que é também matéria da poesia para mostrar isso em um excerto de (guião), que encerra este artigo com o risco, com a incursão no desconhecido como ensejo ao pensamento: “(...) (O dramático esforço de Orfeu, que desce aos infernos para reunir a sua dispersão na unidade final do canto, é tarefa para cada um - e isso nos baste, mesmo que não sirva para nada, além de servir para a possível salvação de quem nela se empenhe) " (HELDER, 1995, p.141-142).

\section{Referências}

ALLOA, Emmanuel. Virada icônica: um apelo por três voltas no parafuso. MODOS. Revista de História da Arte, v. 3, n. 1, p. 91-113, 2019.

BARTHES, Roland. O prazer do texto. Tradução de J. Guinsburg. São Paulo: Perspectiva,

1987.

BELO, Ruy. Na senda da poesia. 2. ed. Lisboa: Assírio \& Alvim, 2002

BLANCHOT, Maurice. A Inspiração. In: O Espaço Literário. Rio de Janeiro: Rocco, 1987, p.161-188.

BLUMENBERG. Hans. The legitimacy of the modern age. (Studies in contemporary German social thought). Tradição de Robert M. Wallace. Massachusetts: MIT Press, 1983.

BLUMENBERG, Hans. Imitação da natureza. Contribuição à pré-história da ideia do homem criador. Tradução de Luiz Costa Lima. In: LIMA, Luiz Costa Lima (org.). Mímesis e a reflexão contemporânea. Rio de Janeiro: EdUerj, 2010, p.87-135. 
BLUMENBERG, Hans. Teoria da não conceitualidade. Tradução de Luiz Costa Lima. Belo Horizonte: Ed. UFMG, 2013.

BRUNEL, Pierre. As vocações de Orfeu. In: BRICOUT, Bernadette (org.). O olhar de Orfeu: os mitos literários do Ocidente. Tradução de L. O. Benoit. São Paulo: Companhia das Letras, 2003. p. 39-62.

COMPAGON, Antoine. O trabalho da citação. Tradução Cleonice Mourão. Belo Horizonte: Editora UFMG, 1996.

COMPAGNON, Antoine. Os cinco paradoxos da modernidade. Tradução de Cleonice Mourão, Belo Horizonte: Editora UFMG, 1999.

EIRAS, Pedro. Esquecer Fausto: a fragmentação do sujeito em Raul Brandão, Fernando Pessoa, Herberto Helder e Maria Gabriela Llansol. Porto: Campo das Letras, 2005.

FRIEDRICH, Hugo. A estrutura da lírica moderna. Tradução Marise Curioni. São Paulo: Duas Cidades, 1978.

GUSMÃO, Manuel. $\mathrm{HH}^{2}$ : In: Revista Textos Pretextos, Lisboa, n. 17: Herberto Helder, p. 56-58, outono-inverno 2012.

GUSMÃO, Manuel. A Estrela Plenária. In: GUSMÃO, Manuel. Tatuagem e Palimpsesto: da Poesia em Alguns Poetas e Poemas. Lisboa: Assírio e Alvim, 2010, p.367-387.

HASSAN, Ihab. PRELUDE: Lyre Without Strings. In: HASSAN, Ihab. Dismemberment of Orpheus: toward a postmodern literature. 2th Ed. Wisconsin: University of Wisconsin Press, 1982, p. 3-23.

HELDER, Herberto. Photomaton \& Vox. Lisboa: Assírio \& Alvim, 1995.

HELDER, Herberto. Poemas Canhotos. Lisboa: Assírio \& Alvim, 2015.

HELDER, Herberto. Poemas Completos. Rio de Janeiro: Tinta 


\section{Da invenção mais impura: uma montagem de Orfeu em Herberto Helder}

da China, 2014.

HELDER, Herberto. Texto em forma de "auto-entrevista" publicado no jornal Público, 4 de Dezembro de 1990, pp. 29-31. HELDER, Herberto. Vinte e cinco cartas, apresentadas por Gastão Cruz. Relâmpago, Lisboa, n. 36-37, Abr./Out., p. 137195, 2015b.

LOPES, Silvina Rodrigues. A inocência do devir: ensaio a partir da obra de Herberto Helder. Lisboa: Edições Vendaval, 2003.

MARTELO, Rosa Maria. Os nomes da obra: Herberto Helder ou O poema contínuo. Documenta, 2016.

NANCY, Jean-Luc. Demanda: Literatura e Filosofia. Florianópolis: Ed. UFSC; Chapecó: Argos, 2016. Tradução de João Camillo Penna, Eclair Antonio Almeida Filho, Dirlenvalder Loyolla.

ROSA, António Ramos. Herberto Helder - poeta órfico. In: Poesia, liberdade livre. Lisboa: Livraria Moraes Editora, 1962, p. 149-157.

SEGAL, Charles. Orpheus: the myth of the poet. Baltimore, Maryland: The Johns Hopkins Press Ltd., London. 1989

SISCAR, Marcos. "Responda, cadáver": o discurso da crise na poesia moderna. Alea, Rio de Janeiro,v. 9, n. 2, p. 176189, Dec. 2007. Disponível em: <http://www.scielo.br/scielo. php?script=sci_arttext\&pid=S1517-106X2007000200003\&lng $=$ en\&nrm=iso $>$. Acesso em: Agosto de 2020 . 